\title{
Metabolite Profiling of Arabidopsis Inoculated with Alternaria brassicicola Reveals That Ascorbate Reduces Disease Severity
}

\author{
Christopher J. Botanga, ${ }^{1,2}$ Gerit Bethke, ${ }^{1}$ Zhong Chen, ${ }^{3}$ Daniel R. Gallie, ${ }^{3}$ Oliver Fiehn, ${ }^{4}$ and \\ Jane Glazebrook ${ }^{1}$
}

${ }^{1}$ Department of Plant Biology and Microbial and Plant Genomics Institute, University of Minnesota, Rm 250 BioSciences Center, 1445 Gortner Ave., St. Paul 55108, U.S.A.; ${ }^{2}$ Department of Biological Sciences, Chicago State University, Rm 310 Williams Science Center, 9501 S. King Drive, Chicago 60628; ${ }^{3}$ Department of Biochemistry, University of California, Riverside 92521-0129, U.S.A.; and ${ }^{4}$ University of California at Davis Genome Center, GBSF Building Room 1315, 451 East Health Sciences Drive, Davis 95616-8816, U.S.A.

Submitted 17 July 2012. Accepted 24 August 2012.

\begin{abstract}
The interaction between the pathogenic ascomycete Alternaria brassicicola and Arabidopsis was investigated by metabolite profiling. The effect of $A$. brassicicola challenge on metabolite levels was substantial, with nearly $50 \%$ of detected compounds undergoing significant changes. Mutations blocking ethylene, jasmonic acid, or ethylene signaling had little effect on metabolite levels. The effects of altering levels of some metabolites were tested by exogenous application during $A$. brassicicola inoculation. Gamma amino-butyric acid (GABA) or xylitol promoted, while trehalose and ascorbate inhibited, disease severity. GABA promoted, and ascorbate strongly inhibited, fungal growth in culture. Arabidopsis vtc1 and vtc2 mutants, that have low levels of ascorbate, were more susceptible to $A$. brassicicola. Ascorbate levels declined following A. brassicicola inoculation while levels of dehydroascorbate increased, resulting in a shift of the redox balance between these compounds in the direction of oxidation. These results demonstrate that ascorbate is an important component of resistance to this pathogen.
\end{abstract}

Necrotrophic fungal pathogens extract nutrients from plants by killing the host tissue and digesting the remains. This is a very different lifestyle from those of biotrophic pathogens, which extract nutrients from living plant tissue. Unsurprisingly, effective plant defense against necrotrophs is also very different from mechanisms effective against biotrophs. In the case of biotrophs, host recognition of pathogen effectors (molecules produced by pathogens that promote virulence) by cognate resistance $(\mathrm{R})$ proteins often triggers a cell death response that is thought to deprive the pathogen of nutrients (Jones and Dangl 2006). Such a response seems unlikely to be effective against necrotrophs, and no R-protein-mediated resistance responses against necrotrophs are known.

Three plant hormones-salicylic acid (SA), jasmonic acidisoleucine conjugate (JA-Ile), and ethylene-are involved in signaling processes that lead to activation of plant defense responses. SA is critical for resistance to many biotrophs, whereas

Corresponding author: J. Glazebrook; E-mail: jglazebr@umn.edu

*The $\boldsymbol{e}$-Xtra logo stands for "electronic extra" and indicates that three supplementary figures and one supplementary table are published online.
JA-Ile and ethylene are important for resistance to necrotrophs, although there are many exceptions to this rule of thumb (Glazebrook 2005). Furthermore, in many situations, SA and JA-Ile signaling interact negatively. Some pathogens exploit this situation to their own advantage, as in the case of the bacterial pathogen Pseudomonas syringae pv. tomato (DC3000), which produces coronatine, a molecular mimic of JA-Ile that suppresses the SA signaling that otherwise limits growth of this pathogen (Spoel and Dong 2008).

Alternaria brassicicola is an ascomycete fungus that causes black spot disease on cultivated Brassica spp., including cabbage and canola. Like other members of the genus, it produces toxic secondary metabolites that cause cell death in plants (Otani et al. 1998). Arabidopsis thaliana is generally highly resistant, with most wild-type accessions suffering only localized cell death at the site of inoculation, with minimal growth and reproduction of the fungus (Thomma et al. 1998). Arabidopsis can serve as a host for Alternaria brassicicola, because at least one accession, Col-6, is susceptible (Kagan and Hammerschmidt 2002; Oh et al. 2005). Resistance in the commonly studied accession Col-0 is not due to failure of the fungus to recognize the plant, neither are preformed plant defenses sufficient for resistance. Previous work has demonstrated that JA-Ile signaling, camalexin synthesis, and a host lipase called GLIP1 are all needed for resistance. Thus, the A. brassicicolaArabidopsis system serves as a model for plant resistance to necrotrophic fungi.

The evidence for which plant defenses are needed for resistance to A. brassicicola is based on Arabidopsis genetics. Mutants such as $d d e 2$, which lacks an allene oxide synthase required for JA synthesis, or coil, which lacks an F-box protein that serves as the JA-Ile receptor, are susceptible to A. brassicicola (Thomma et al. 1998; van Wees et al. 2003). Evidently, defense responses under JA-Ile control are important for resistance. Mutations that block SA or ethylene signaling do not reduce resistance. In response to attempted infection by $A$. brassicicola or other pathogens, Arabidopsis produces a phytoalexin called camalexin. Mutations that reduce camalexin levels, including cyp79B2 cyp79B3 (blocks conversion of tryptophan to indole-3-acetaldoxime [IAOx]) (Glawischnig et al. 2004; Hull et al. 2000; Mikkelsen et al. 2000), cyp71A13 (blocks conversion of IAOx to indole-3-acetonitrile [IAN]) (Nafisi et al. 2007), pad2 (reduces synthesis of glutathione, donor of the cysteine ring) (Parisy et al. 2007; Su et al. 2011), 
or cyp71B15 (blocks conversion of CysIAN to camalexin) (Böttcher et al. 2009; Schuhegger et al. 2006) cause susceptibility to A. brassicicola (Nafisi et al. 2007; Thomma et al. 1999b; van Wees et al. 2003). Camalexin levels are not reduced in coil plants; therefore, the effects of camalexin and JA-Ile signaling on resistance to A. brassicicola appear to be independent (Thomma et al. 1999b; van Wees et al. 2003). Plants with glipl mutations fail to produce the secreted lipase GLIP1 and are susceptible to A. brassicicola (Oh et al. 2005). GLIP1 protein inhibits fungal growth in culture; therefore, it may contribute to resistance through this anti-fungal activity (Oh et al. 2005).

Mannitol produced by Alternaria spp. plays a role in pathogenesis. Alternaria alternata, a close relative of $A$. brassicicola, secretes mannitol when exposed to host plant extracts, and its tobacco host, a plant that does not produce mannitol, produces a mannitol dehydrogenase in response to fungal attack (Jennings et al. 1998). Transgenic tobacco overexpressing a mannitol dehydrogenase shows increased resistance to A. alternata (Jennings et al. 2002). A. alternata mutants that do not produce mannitol cause much less severe disease on tobacco (Vélëz et al. 2008). The mechanism by which mannitol promotes virulence remains to be elucidated.

In this work, we have characterized the A. brassicicolaArabidopsis interaction by metabolite profiling. Infection had a major effect on the plant metabolite profile, with levels of nearly half of metabolites detected undergoing significant changes. Several metabolites whose levels changed during the interaction were found to affect disease severity when added exogenously. In particular, levels of ascorbate declined during infection, exogenous ascorbate reduced disease severity, and mutant plants with reduced ascorbate levels were more susceptible to A. brassicicola.

\section{RESULTS}

\section{A. brassicicola challenge has a major effect on Arabidopsis metabolite levels.}

We carried out a metabolite profiling experiment to explore the effect of $A$. brassicicola challenge on Arabidopsis metabolite levels. We included defense signaling mutants with defects in major defense signaling sectors: $d d e 2$, which fails to produce JA-Ile; ein2, which fails to respond to ethylene; and sid2, which fails to produce SA. Plants were inoculated with $A$. brassicicola by applying droplets of water containing fungal spores to the surface of leaves. Quantitative polymerase chain reaction (qPCR) was used to measure the ratio of fungal to plant DNA in leaf discs of constant size. The amount of fungal DNA increases as the fungus grows, and the amount of plant DNA decreases as the fungus destroys plant tissue; therefore, this ratio serves as a useful measure of disease severity (Berr et al. 2010; Gachon and Saindrenan 2004; Tsuda et al. 2009; van Wees et al. 2003). Mutant dde2 allows more growth of A. brassicicola than wild-type plants, although to a lesser extent than the highly susceptible pad3 mutant, while ein 2 and sid 2 retain wild-type levels of resistance (Fig. 1). This is consistent with previous reports that coil, which fails to respond to JA-Ile, displays increased susceptibility to A. brassicicola, whereas mutations in sid2 and ein2 have no effect (van Wees et al. 2003).

For metabolite profiling, plants of each genotype (wild-type Col-0, dde2, ein2, and sid2) were inoculated with A. brassicicola spores or mock inoculated with water, and samples were collected after 9 and $24 \mathrm{~h}$. Samples from six independent experiments were collected. Some samples did not yield data of acceptable quality but at least five useful replicate profiles were obtained for each genotype-time-treatment combination.
The metabolite profiles consisted of 570 compounds, of which 148 could be identified. Using a mixed linear model, with genotype, time, and treatment as factors (discussed below), we tested the data for metabolites whose levels were significantly ( $\mid \log _{2}$ fold-change $\mid>0.4, q<0.05$ ) different from wild-type Col-0 in any time-treatment combination in any genotype. In all, 37 metabolites, of which 15 were identified, met these conditions (Supplementary Table S1). Most metabolites were significantly altered in only one genotype, at only one time-treatment combination. There were six exceptions, including four identified compounds: mannonic acid, high in sid 2 at $9 \mathrm{~h}$ in both mock and inoculated samples; myo-inositol, high in ein2 at $9 \mathrm{~h}$ in both mock and inoculated samples, and high in ein2 at $24 \mathrm{~h}$ in inoculated samples; fumaric acid, low in ein 2 at $24 \mathrm{~h}$ in both mock and inoculated samples; and the ethylene precursor 1-aminocyclopropanecarboxylic acid (ACC), high in dde2and ein2-inoculated samples at $24 \mathrm{~h}$. JA-Ile and ethylene signaling are known to act synergistically in control of some defense responses. Because synthesis of ACC is the rate-limiting step in ethylene production, our data suggest that both lack of JAIle and failure to respond to ethylene cause increased ethylene synthesis during the response to A. brassicicola.

Using the model with genotype, time, and treatment as factors, 27 and 56 compounds were significantly (|log $\log _{2}$ foldchange $>0.4, q<0.05$ ) affected by inoculation of Col-0 at 9 and $24 \mathrm{~h}$, respectively. Because levels of few compounds were affected in any individual mutant, we decided to increase statistical power by dropping genotype as a factor and repeating the analysis using a mixed linear model with only time and treatment as factors. In this analysis, 128 and 249 compounds were significantly ( $\mid \log _{2}$ fold-change $\mid>0.4, q<0.05$ ) affected by inoculation of Col- 0 at $9 \mathrm{~h}$ and $24 \mathrm{~h}$, respectively. Identified compounds meeting this condition are listed in Table 1 . Half of the compounds whose levels decreased $9 \mathrm{~h}$ after inoculation remained decreased at $24 \mathrm{~h}$, whereas nearly all of the compounds that increased $9 \mathrm{~h}$ after inoculation remained increased at $24 \mathrm{~h}$ (Fig. 2). Overall, inoculation with A. brassicicola had a major effect on metabolite levels, with nearly half of all compounds detected undergoing changes.

Although mannitol is known to be produced by A. alternata, it was not identified in our automated BinBase analysis. Mannitol was found with an average of 114-fold change between

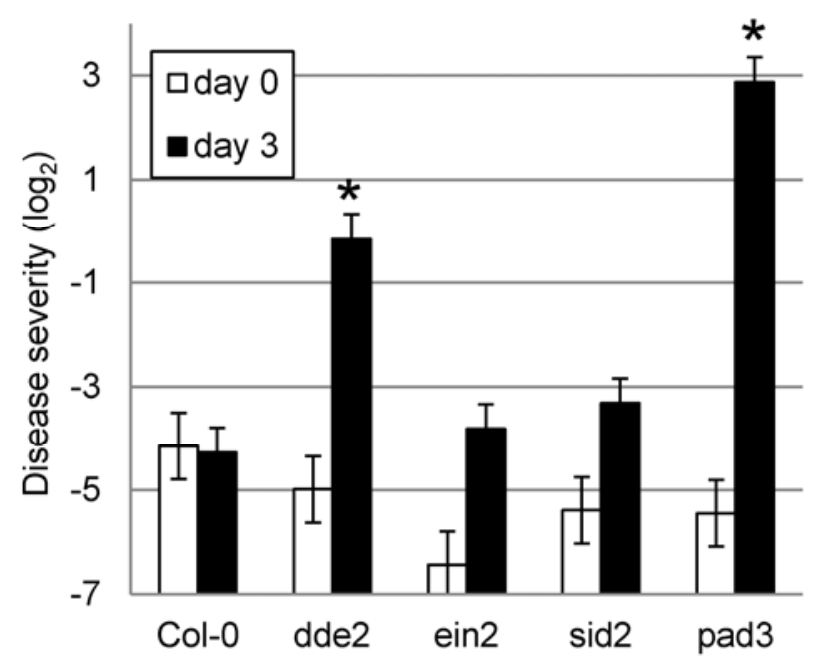

Fig. 1. Growth of Alternaria brassicicola in various Arabidopsis genotypes. Data are from two independent experiments, each with two technical replicates, analyzed using separate mixed linear models for the 0and 3-day time points. Error bars are standard error. Asterisks indicate significant differences from Col-0 at 3 days $(P<0.01)$. 
mock- and A. brassicicola-infected plants. In order to cover this wide range of detected metabolite levels, mannitol abundances were quantified in a targeted manner by peak areas at $\mathrm{m} / \mathrm{z} 319$. For very abundant compounds, peak areas yield more accurate values than peak heights, the default setting for automatic evaluations in BinBase. Mannitol was present in much higher levels in A. brassicicola-inoculated samples than in mock-inoculated samples $\left(P<10^{-46}\right.$, Student's $t$ test) (Supplementary Fig. S1).

\section{Application of some metabolites}

during $A$. brassicicola inoculation affects fungal growth.

To test for effects of altered metabolite levels on fungal growth, selected metabolites were added to A. brassicicola inoculum and applied to plants. Metabolites were chosen based on commercial availability, our observation that levels of several sugar alcohols changed following inoculation, and previous reports of compounds affecting plant-pathogen interactions or plant responses to stress. Because wild-type Col-0 is very resistant to $A$. brassicicola, we used $d d e 2$ plants for these experiments, thinking that the increased susceptibility of $d d e 2$ plants might allow detection of reduced as well as increased fungal growth. The metabolites tested included ascorbate (both ascorbate and dehydroascorbate [DHA] were reduced by inocu- lation), trehalose (increased more than 16-fold), gamma aminobutyric acid (GABA; increased), glucose (decreased), mannitol (increased), myo-inositol (modestly decreased), and xylitol (unchanged). Treatment with GABA at 10 or $100 \mathrm{mg} / \mathrm{ml}$ or xylitol at $100 \mathrm{mg} / \mathrm{ml}$ in the inoculation droplets significantly increased disease severity relative to water treatment, whereas ascorbate at $100 \mathrm{mg} / \mathrm{ml}$ and trehalose at 10 or $100 \mathrm{mg} / \mathrm{ml} \mathrm{sig-}$ nificantly decreased disease severity (Fig. 3).

\section{GABA promotes and ascorbate inhibits}

$A$. brassicicola growth in culture.

One possible explanation for effects of added metabolites on disease severity is that altering levels of these metabolites affects fungal pathogenicity or plant defense. Another possibility is that they have direct effects on fungal growth. To test the latter hypothesis, we grew A. brassicicola on minimal medium. We provided the various metabolites or glucose as carbon sources to test for the ability of $A$. brassicicola to grow on these compounds. A. brassicicola was able to use mannitol, myo-inositol, trehalose, and xylitol as carbon sources (Fig. 4A), although growth was somewhat less robust than on glucose. We also supplemented medium containing $1 \%$ glucose with $20 \mathrm{mM}$ each of the various metabolites to test for effects on fungal growth. Supplementation with GABA enhanced fun-

Table 1. Compounds significantly increased or decreased after Alternaria brassicicola inoculation ${ }^{\mathrm{a}}$

\begin{tabular}{|c|c|c|c|c|}
\hline Compound & FC, $9 \mathrm{~h}$ & FC, $24 \mathrm{~h}$ & $q, 9 \mathrm{~h}$ & $q, 24 \mathrm{~h}$ \\
\hline 1,2,4-Benzenetriol & -0.51 & -0.29 & $9.27 \mathrm{E}-03$ & $1.03 \mathrm{E}-01$ \\
\hline 1,2-Anhydro-myo-inositol & -0.42 & -0.51 & $1.23 \mathrm{E}-03$ & $2.08 \mathrm{E}-04$ \\
\hline Pyrazine 2,5-dihydroxy & 0.15 & 0.89 & $2.41 \mathrm{E}-01$ & $1.01 \mathrm{E}-04$ \\
\hline 1Aminocyclopropane carboxylic acid & 0.25 & 0.92 & $1.99 \mathrm{E}-01$ & $2.41 \mathrm{E}-03$ \\
\hline 2-Ketoglucose dimethylacetal & 0.3 & -0.72 & $1.78 \mathrm{E}-01$ & $1.99 \mathrm{E}-02$ \\
\hline 2-Methylglyceric acid & 2.07 & 2.46 & $1.64 \mathrm{E}-16$ & $2.68 \mathrm{E}-19$ \\
\hline 2-Monoolein & 0.11 & 1.6 & $2.67 \mathrm{E}-01$ & $9.64 \mathrm{E}-13$ \\
\hline 3-Deoxyhexitol & 4.13 & 3.69 & $1.12 \mathrm{E}-16$ & $9.71 \mathrm{E}-14$ \\
\hline 4-Hydroxyphenyl-2-ethylglucopyranoside & 1.29 & 2.04 & $3.90 \mathrm{E}-03$ & $2.34 \mathrm{E}-05$ \\
\hline Alanine & 0.66 & -0.04 & 2.91E-04 & $3.66 \mathrm{E}-01$ \\
\hline Arabinose & -0.48 & -0.67 & $7.25 \mathrm{E}-04$ & $9.95 \mathrm{E}-06$ \\
\hline Arabitol & 4.45 & 5.39 & $2.84 \mathrm{E}-23$ & 4.49E-27 \\
\hline Ascorbic acid & -0.4 & -1.71 & $1.17 \mathrm{E}-01$ & 7.03E-07 \\
\hline Asparagine & -0.43 & -1.01 & 4.42E-02 & $3.18 \mathrm{E}-05$ \\
\hline Aspartic acid & -0.86 & -0.87 & $1.17 \mathrm{E}-02$ & $1.40 \mathrm{E}-02$ \\
\hline Beta alanine & 0.02 & 1.89 & $4.09 \mathrm{E}-01$ & $1.70 \mathrm{E}-04$ \\
\hline Beta sitosterol & 0.03 & -0.67 & $3.86 \mathrm{E}-01$ & $5.43 \mathrm{E}-03$ \\
\hline Butylamine & -0.45 & -0.6 & $4.45 \mathrm{E}-02$ & $1.31 \mathrm{E}-02$ \\
\hline Butyrolactam & -0.34 & -0.5 & $1.13 \mathrm{E}-01$ & $4.92 \mathrm{E}-02$ \\
\hline Cellobiotol & 0.05 & 0.44 & 3.37E-01 & $5.76 \mathrm{E}-03$ \\
\hline Cholesterol & -0.28 & -0.45 & $9.83 \mathrm{E}-02$ & $2.50 \mathrm{E}-02$ \\
\hline Conduritol-beta-epoxide & 1.9 & 3.49 & $2.19 \mathrm{E}-14$ & 4.49E-27 \\
\hline Cyano-L-alanine & 0.04 & 1.01 & $3.93 \mathrm{E}-01$ & $3.13 \mathrm{E}-03$ \\
\hline Cysteine & 0.35 & 1.82 & $2.27 \mathrm{E}-01$ & $1.83 \mathrm{E}-04$ \\
\hline Dehydroabietic acid & -0.81 & -0.23 & $1.92 \mathrm{E}-02$ & $2.62 \mathrm{E}-01$ \\
\hline Dehydroascorbate & -0.14 & -1.25 & $3.31 \mathrm{E}-01$ & $1.46 \mathrm{E}-03$ \\
\hline Epsilon-caprolactam & -0.65 & -0.2 & 4.00E-02 & $2.72 \mathrm{E}-01$ \\
\hline Erythrose & -0.97 & -0.94 & $8.24 \mathrm{E}-03$ & $1.33 \mathrm{E}-02$ \\
\hline Ethanolamine & -1.1 & -0.16 & $1.42 \mathrm{E}-02$ & $3.40 \mathrm{E}-01$ \\
\hline FAD & -0.04 & 0.4 & $3.59 \mathrm{E}-01$ & $1.33 \mathrm{E}-02$ \\
\hline Fructose & -0.19 & -0.66 & $1.39 \mathrm{E}-01$ & $1.32 \mathrm{E}-04$ \\
\hline Fructose-6-phosphate & -0.58 & -0.56 & $1.14 \mathrm{E}-02$ & $1.86 \mathrm{E}-02$ \\
\hline Gamma amino-butyric acid & 0.5 & 1.1 & $3.68 \mathrm{E}-03$ & 7.99E-09 \\
\hline Galactonic acid & -0.57 & -1.06 & $1.23 \mathrm{E}-01$ & $2.16 \mathrm{E}-02$ \\
\hline Glucose & -0.27 & -0.51 & $7.02 \mathrm{E}-02$ & $3.27 \mathrm{E}-03$ \\
\hline Glucose-1-phosphate & -0.84 & -0.57 & $3.16 \mathrm{E}-04$ & $1.48 \mathrm{E}-02$ \\
\hline Glucose-6-phosphate & -0.55 & -0.76 & $2.08 \mathrm{E}-02$ & $3.10 \mathrm{E}-03$ \\
\hline Glucuronic acid & -0.05 & 0.56 & $3.48 \mathrm{E}-01$ & $1.09 \mathrm{E}-03$ \\
\hline Glutamic acid & 1.02 & 1.56 & $2.00 \mathrm{E}-02$ & $9.60 \mathrm{E}-04$ \\
\hline Glycerol-alpha-phosphate & -0.05 & 1.05 & $3.50 \mathrm{E}-01$ & $1.05 \mathrm{E}-07$ \\
\hline Glycine & 0.83 & 2.16 & $1.06 \mathrm{E}-01$ & 8.24E-04 \\
\hline Homoglutamine & -0.93 & -1.43 & $6.49 \mathrm{E}-05$ & $1.73 \mathrm{E}-08$ \\
\hline
\end{tabular}

${ }^{\text {a }}$ FC indicates fold change inoculated mock ( $\log _{2}$ scale) and $q$ indicates significance value for the associated fold change. 
gal growth, ascorbate completely abolished growth, and mannitol, myo-inositol, trehalose, and xylitol had no effect (Fig. 4B). We further explored the effect of ascorbate by supplementing minimal glucose medium with varying amounts of ascorbate. Overall, $25 \mu \mathrm{M}$ was sufficient to inhibit growth and no growth was observed at $10 \mathrm{mM}$ (Fig. 4C). Taken together, these results show that GABA enhances and ascorbate inhibits growth of $A$. brassicicola in culture. Thus, the effects of exogenous ascorbate and GABA on A. brassicicola growth on plants can be explained by the effects of these compounds on fungal growth in general. However, xylitol, mannitol, and trehalose only affect fungal growth on plants.

\section{Altered plant GABA levels do not affect \\ A. brassicicola disease severity.}

Interpretation of the effects of exogenously added compounds on disease severity is difficult because the extent to which they enter plant tissues and the endogenous levels in inoculated leaves are not known. Therefore, we tested for altered disease severity in Arabidopsis mutants known to have altered levels of compounds of interest. To test whether plant GABA promotes fungal growth during infection, we obtained Arabidopsis mutants previously shown to have altered GABA metabolism. GABA transaminase, encoded by POP2 (At3g22200), transfers an amino group from GABA to pyruvate, yielding alanine and succinic semi-aldehyde which, in turn, is converted to succinate or 4-hydroxybutyrate (Palanivelu et al. 2003; Shelp et al. 1999). The pop2-1 mutant (Ler background) has leaf GABA levels that are 20 to 100 times higher than Ler (Palanivelu et al. 2003; Park et al. 2010). We tested disease severity 7 days after inoculation with A. brassicicola in pop2-1, Ler, Col-0, and three T-DNA insertion alleles in At3g22200 in the Col background. None of the mutants displayed disease severity that was significantly different from the corresponding wildtype genotype (Supplementary Fig. S2). We conclude that, although GABA levels rise during infection and exogenous GABA promotes A. brassicicola disease severity, increased plant GABA levels are not sufficient to cause a significant difference in disease severity.

\section{Reduction in ascorbic acid levels increases}

A. brassicicola disease severity.

Addition of ascorbate reduced $A$. brassicicola disease severity (Fig. 3A) and strongly inhibited A. brassicicola growth in culture. We hypothesized that plants with reduced levels of ascorbate might show enhanced susceptibility to A. brassicicola. VTC1 encodes a GDP-mannose pyrophosphorylase (Conklin et al. 1999), while VTC2 encodes GDP-L-Gal phosphorylase (Dowdle et al. 2007; Linster et al. 2007). Plants homozygous for the $v t c 1-1$ or $v t c 2-1$ missense mutations have greatly reduced

Table 1. (continued from preceding page)

\begin{tabular}{|c|c|c|c|c|}
\hline Compound & FC, 9 h & FC, 24 h & $q, 9 \mathrm{~h}$ & $q, 24 \mathrm{~h}$ \\
\hline Homoserine & 0.16 & 0.64 & $2.25 \mathrm{E}-01$ & $3.13 \mathrm{E}-03$ \\
\hline Hydroxylamine & -0.77 & -0.57 & $8.43 \mathrm{E}-03$ & $4.81 \mathrm{E}-02$ \\
\hline Idonic acid & -0.32 & 0.65 & $9.88 \mathrm{E}-02$ & $6.21 \mathrm{E}-03$ \\
\hline Indole-3-acetate & -0.15 & 2.71 & $2.57 \mathrm{E}-01$ & $2.10 \mathrm{E}-18$ \\
\hline Inositol allo- & 2.12 & 2.57 & $6.83 \mathrm{E}-15$ & 7.12E-18 \\
\hline Inositol myo- & -0.25 & -0.52 & $8.45 \mathrm{E}-02$ & $2.41 \mathrm{E}-03$ \\
\hline Isonicotinic acid & -0.6 & 0.33 & $2.52 \mathrm{E}-04$ & $3.78 \mathrm{E}-02$ \\
\hline Isothreonic acid & -0.24 & 0.5 & $8.36 \mathrm{E}-02$ & $2.30 \mathrm{E}-03$ \\
\hline Leucine & -0.16 & 0.49 & $1.82 \mathrm{E}-01$ & $5.43 \mathrm{E}-03$ \\
\hline Levoglucosan & -1.01 & -1.42 & $1.14 \mathrm{E}-03$ & $1.82 \mathrm{E}-05$ \\
\hline Linoleic acid & 0.23 & 0.76 & $9.33 \mathrm{E}-02$ & $5.87 \mathrm{E}-06$ \\
\hline Lysine & -0.45 & 1.12 & $9.29 \mathrm{E}-04$ & $9.91 \mathrm{E}-13$ \\
\hline Maltose & -1.29 & -0.04 & $1.81 \mathrm{E}-02$ & 4.02E-01 \\
\hline Melibiose & 0.9 & 1.61 & $5.12 \mathrm{E}-06$ & $5.55 \mathrm{E}-13$ \\
\hline Methionine & -0.61 & 0.46 & $2.83 \mathrm{E}-03$ & $2.56 \mathrm{E}-02$ \\
\hline Methionine sulfoxide & -0.07 & 0.53 & $2.45 \mathrm{E}-01$ & $3.76 \mathrm{E}-06$ \\
\hline Mevalonic acid & -0.19 & 0.81 & $1.97 \mathrm{E}-01$ & $3.73 \mathrm{E}-04$ \\
\hline$N$-acetyl-D-hexosamine & -0.09 & 1.2 & 3.38E-01 & $1.49 \mathrm{E}-05$ \\
\hline$O$-acetylserine & 0.74 & 1.23 & $1.74 \mathrm{E}-02$ & 2.91E-04 \\
\hline Octadecanol & -0.61 & -0.2 & $2.40 \mathrm{E}-02$ & $2.41 \mathrm{E}-01$ \\
\hline Oleic acid & 0.2 & 1.48 & $1.66 \mathrm{E}-01$ & $2.48 \mathrm{E}-11$ \\
\hline Ornithine & 0.3 & 0.57 & $1.07 \mathrm{E}-01$ & $1.29 \mathrm{E}-02$ \\
\hline Palatinitol & 0.38 & 2.26 & $6.41 \mathrm{E}-02$ & $4.05 \mathrm{E}-16$ \\
\hline Palmitic acid & -0.26 & 0.42 & $1.20 \mathrm{E}-01$ & $3.93 \mathrm{E}-02$ \\
\hline Pentadecanoic acid & 0.24 & 0.84 & $1.61 \mathrm{E}-01$ & $4.15 \mathrm{E}-04$ \\
\hline Phenylalanine & 0.24 & 0.45 & $5.86 \mathrm{E}-02$ & $2.02 \mathrm{E}-03$ \\
\hline Phosphoric acid & 0.49 & -1.39 & $9.45 \mathrm{E}-02$ & $1.37 \mathrm{E}-04$ \\
\hline Phytol & -0.15 & 0.54 & $2.14 \mathrm{E}-01$ & $5.28 \mathrm{E}-03$ \\
\hline Pipecolic acid & 0.4 & 3.06 & $2.29 \mathrm{E}-01$ & $1.68 \mathrm{E}-07$ \\
\hline Proline & -0.44 & -0.21 & $6.27 \mathrm{E}-03$ & $1.25 \mathrm{E}-01$ \\
\hline Putrescine & 0.37 & 1.18 & $6.12 \mathrm{E}-02$ & $5.60 \mathrm{E}-07$ \\
\hline Ribose & -0.4 & 0.72 & $9.23 \mathrm{E}-03$ & $1.83 \mathrm{E}-05$ \\
\hline Serine & -0.48 & 0.73 & $2.46 \mathrm{E}-03$ & $1.49 \mathrm{E}-05$ \\
\hline Shikimic acid & -0.18 & 0.54 & $1.36 \mathrm{E}-01$ & 8.19E-04 \\
\hline Sophorose & -0.95 & 0.21 & $4.52 \mathrm{E}-05$ & $1.97 \mathrm{E}-01$ \\
\hline Spermidine & -0.36 & -0.94 & $7.02 \mathrm{E}-02$ & 8.34E-05 \\
\hline Stigmasterol & 0.37 & 3.75 & $1.51 \mathrm{E}-01$ & $3.09 \mathrm{E}-18$ \\
\hline Succinic acid & 0.9 & 0.88 & $1.17 \mathrm{E}-03$ & $2.14 \mathrm{E}-03$ \\
\hline Sucrose & -0.36 & -1.04 & $6.99 \mathrm{E}-04$ & $6.27 \mathrm{E}-16$ \\
\hline Threonic acid & -0.16 & 0.95 & $1.73 \mathrm{E}-01$ & $8.51 \mathrm{E}-08$ \\
\hline Trehalose & 4.15 & 4.49 & $3.54 \mathrm{E}-43$ & $5.25 \mathrm{E}-44$ \\
\hline Tryptophan & 0.34 & 1.46 & 8.39E-02 & $6.54 \mathrm{E}-09$ \\
\hline Tyrosine & 0 & 0.88 & 4.13E-01 & $3.57 \mathrm{E}-05$ \\
\hline Uric acid & -1.22 & -2.55 & $2.03 \mathrm{E}-03$ & 7.43E-09 \\
\hline
\end{tabular}


foliar ascorbate levels (Conklin et al. 1997, 2000). DHA reductase (DHAR) and monodehydroascorbate reductase (MDHAR) recycle oxidized DHA back to ascorbate. Overexpression of genes encoding these enzymes can increase ascorbate levels (Chen et al. 2003); therefore, we produced Arabidopsis transgenic plants overexpressing wheat DHAR, maize MDHAR, or both. We tested wild-type, vtc1-1, vtc2-1, plants overexpressing DHAR (DHAR1), plants overexpressing MDHAR (MDHAR3), and plants overexpressing both DHAR and MDHAR (DHAR1+MDHAR3) for A. brassicicola disease severity. Both $v t c 1-1$ and vtc2-1 plants were significantly more susceptible to A. brassicicola than wild-type plants, whereas DHAR1, MDHAR3, and DHAR1+MDHAR3 were not significantly different from the wild type (Fig. 5). We determined ascorbate levels in plants of the same age and grown under the same conditions as those used for the disease severity assays. We found that ascorbate levels were greatly reduced in $v t c 1-1$ and $v t c 2-1$ plants (to 30 and $20 \%$ of wild-type levels, respectively, consistent with previous reports) (Conklin et al. 2000). There was a very modest but statistically significant reduction in DHAR1+MDHAR3

\section{Decreased by inoculation}

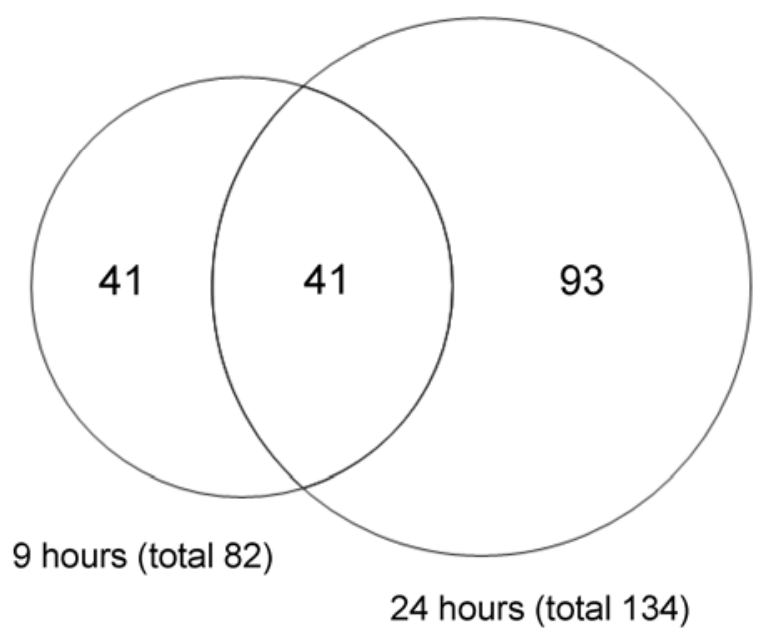

Increased by inoculation

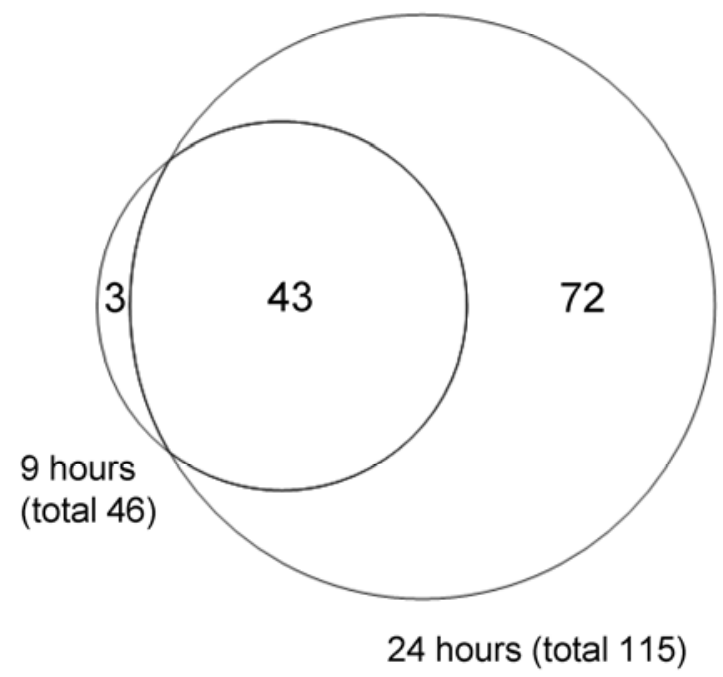

Fig. 2. Metabolites that undergo statistically significant changes after Alternaria brassicicola inoculation. Top panel shows numbers of metabolites decreased relative to mock-treated plants and 9 and $24 \mathrm{~h}$ after inoculation. Bottom panel shows metabolites increased relative to mock. plants (to $91 \%$ of wild-type levels) and no difference in DHAR1 or MDHAR3 plants, although immunoblotting experiments showed that levels of DHAR and MDHAR proteins were markedly increased in transgenic lines (Supplementary Fig. S3). We conclude that host ascorbate levels are important for limiting $A$. brassicicola disease severity in Arabidopsis.

Ascorbate levels are reduced by $\boldsymbol{A}$. brassicicola inoculation.

We have shown that ascorbate plays an important role in resistance to A. brassicicola; therefore, we monitored levels of ascorbate and DHA in inoculated plants using a high-performance liquid chromatography (HPLC) assay, to test the validity of the result from metabolite profiling. Two measurements were made for each sample: ascorbate and ascorbate $+\mathrm{DHA}$ (obtained by reduction of ascorbate to DHA prior to HPLC). Consistent with the metabolite profiling data, the concentrations of ascorbate and ascorbate+DHA were lower in inoculated plants and uninoculated plants at both 9 and $24 \mathrm{~h}$ after inoculation (Fig. 6A and C). However, the amount of DHA increased by $24 \mathrm{~h}$ after inoculation (Fig. 6B), which is not consistent with the metabolite profiling data. Ascorbate and DHA are difficult to determine by metabolite profiling because they can be unstable during sample preparation; therefore, the data from HPLC are more reliable. Interestingly, the ratio of reduced ascorbate to the total ascorbate+DHA declined by $24 \mathrm{~h}$ following inoculation, indicating that the plant tissue became more oxidizing (Fig. 6D). Collectively, our data demonstrate that host ascorbate levels decline following inoculation, the redox state of the host tissue becomes more oxidizing, growth of $A$. brassicicola is inhibited by ascorbate, and reduction of host ascorbate to levels found in $v t c 1$ and $v t c 2$ mutants promotes disease severity in inoculated plants.

\section{DISCUSSION}

To investigate changes in metabolites that might affect resistance to the necrotrophic fungal pathogen, A. brassicicola, we carried out metabolite profiling on Arabidopsis wild-type and mutant plants following A. brassicicola inoculation. It is known that mutations affecting SA or ethylene signaling do not have detectable effects on resistance to A. brassicicola, whereas mutations affecting JA-Ile signaling reduce resistance substantially. We confirmed this, showing that dde 2 plants, which do not produce JA-Ile, showed increased disease severity. Curiously, none of the mutations $d d e 2$, ein2, or sid2 had much effect on levels of the metabolites in our profiles. The nature of the metabolites profiled has been described previously (Kind et al. 2009) and likely represents only a fraction of the metabolites present in plant cells. JA-Ile signaling may exert its effect on resistance through changes in levels of compounds not included in our profiles, or it might act at the level of macromolecules. A. brassicicola inoculation did have a marked effect on metabolite levels. Nearly half of the metabolites detected changed concentration by $30 \%$ or more $\left(\left|\log _{2}\right|>\right.$ $0.4, q<0.05)$, indicating a major change in cell state. In this experimental design, metabolites produced by the fungus cannot be distinguished from those produced by the plant host. Thus, some metabolites undergoing large increases could be produced by the fungus. A likely example is mannitol, which is produced by at least some Alternaria spp. but which has not been reported in Arabidopsis (Jennings et al. 1998).

Our metabolite profiles included auxin (indole-3-acetate) and the ethylene precursor ACC. Both compounds increased significantly by $24 \mathrm{~h}$ after inoculation. Ethylene does not seem to play a major role in defense against $A$. brassicicola, because ein2 mutants do not show increased disease severity (Fig. 1) (Thomma et al. 1999a). However, ethylene and JA-Ile can act 
synergistically in activation of some defense genes; therefore, ethylene may have some role in stabilizing the defense response to A. brassicicola (Penninckx et al. 1998). Auxin has a negative effect on SA signaling which, in turn, has a negative effect on JA-Ile signaling (Robert-Seilaniantz et al. 2011a,b). Some experiments have suggested positive interactions between auxin and JA signaling but there are also conflicting reports (Robert-Seilaniantz et al. 2011a). Elevated auxin levels may contribute positively to defense against $A$. brassicicola by directly or indirectly promoting JA-Ile signaling.

Some of the changes in metabolite levels that we observed following A. brassicicola inoculation also occur following inoculation with the bacterial pathogen $P$. syringae pv. tomato strain DC3000 (Ward et al. 2010). Notably, all three aromatic amino acids (phenylalanine, tryptophan, and tyrosine) increased during both infections. Increased tryptophan may be due to production of camalexin, a phytoalexin synthesized from tryptophan. Perhaps this metabolic flux also causes increases in levels of other aromatic amino acids. Levels of several other amino acids (alanine, glycine, leucine, and lysine) also increased in response to both pathogens. Levels of asparagine, aspartic acid, glutamic acid, and proline showed opposite behavior, with alanine and glutamic acid increasing in response to $A$. brassicicola but decreasing in response to $P$. syringae, and asparagine, aspartic acid, and proline decreasing in response to $A$. brassicicola but increasing in response to $P$. syringae. Putrescine and stigmasterol increased in response to both pathogens, as did the non-protein amino acid GABA and the disaccharide trehalose (Ward et al. 2010).

Trehalose levels increased substantially in response to $A$. brassicicola (16-fold by $9 \mathrm{~h}$ ) (Table 1), and addition of trehalose to inoculation droplets inhibited fungal growth. Trehalose is a nonreducing disaccharide of glucose ( $\alpha, \alpha-1,1$-linked), whose levels rise in response to various abiotic stresses. Plants with constitutively elevated trehalose levels show developmental abnormalities and increased tolerance to abiotic stresses
(Fernandez et al. 2010). There is a family of 11 trehalose synthases in Arabidopsis (Leyman et al. 2001; Paul et al. 2008). One of these, TPS11, is induced by aphid feeding, and tps 11 mutants support more aphid growth (Singh et al. 2011). Expression of the central defense regulator PAD4 is reduced in tps 11 plants, and accumulation of starch is also decreased (Singh et al. 2011). PAD4 is important for aphid resistance but not for resistance to A. brassicicola (Pegadaraju et al. 2007; van Wees et al. 2003). The effect of changes in levels of glucose versus starch on $A$. brassicicola growth in infected plants is not known. It seems likely that trehalose levels increase in response to both abiotic and biotic stresses.

Addition of exogenous GABA promoted growth of $A$. brassicicola on $d d e 2$ plants and in culture. However, mutants with GABA levels elevated as much as 20-fold did not support more growth of $A$. brassicicola. It is possible that this elevation of GABA levels is not sufficient to significantly affect fungal growth in the highly resistant Col-0 and Ler backgrounds. GABA levels also rise in response to infection by $P$. syringae pv. tomato DC3000 (Park et al. 2010; Ward et al. 2010). In this case, GABA suppresses expression of bacterial effector genes, which likely accounts for reduction of pathogen growth in pop 2-1 plants (Park et al. 2010). Bacteria lacking GABA transaminase activity accumulate GABA, and grow very poorly in pop 2-1 plants (Park et al. 2010). A. brassicicola mutants lacking GABA transaminase, or plants with reduced levels of GABA, might reveal a role for GABA in the A. brassicicolaArabidopsis system. GABA is produced from glutamate by glutamate decarboxylase (GAD). Notably, levels of GABA and glutamate were both high in A. brassicicola-inoculated plants. There are five GAD genes in Arabidopsis. Mutation of GAD1 drastically reduces GABA in roots (Bouche et al 2004). If a $G A D$ mutation or combination of mutations that reduces levels of GABA in leaves can be found, it would be possible to test whether this reduces growth of A. brassicicola in a susceptible background such as pad3 or $d d e 2$.

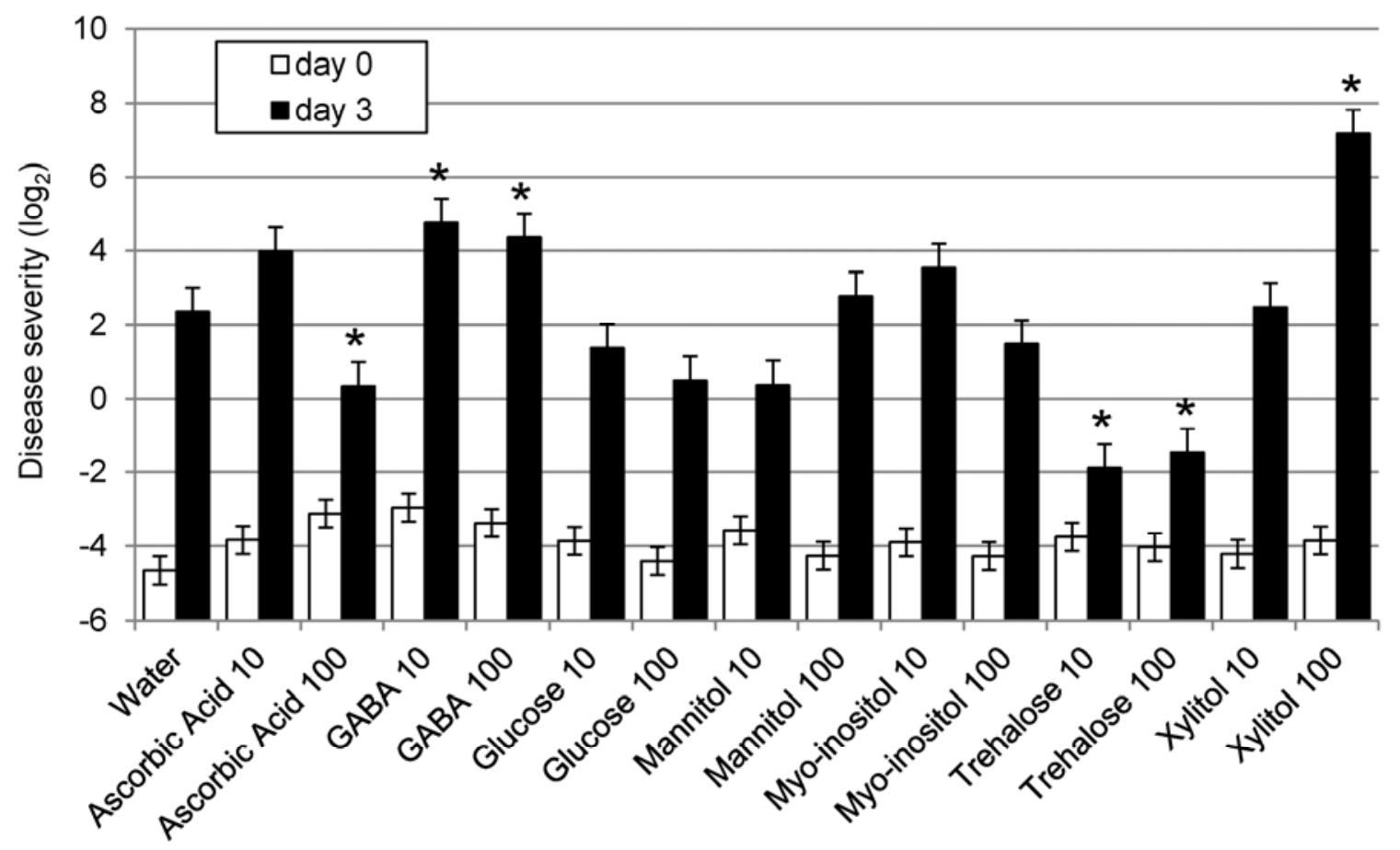

Fig. 3. Disease severity of Alternaria brassicicola in dde 2 plants treated with various compounds at $10 \mathrm{mg} / \mathrm{ml}(10)$ or $100 \mathrm{mg} / \mathrm{ml}(100)$ added to the inoculation droplets. Data are from two independent experiments. Each experiment included two technical replicates, which were combined to give average values for each treatment-time combination. Averages from each experiment were combined and analyzed using mixed linear models. Error bars indicate standard error. Asterisks indicate significant differences from water at 3,4 , or 7 days $(P<0.05)$ 
A

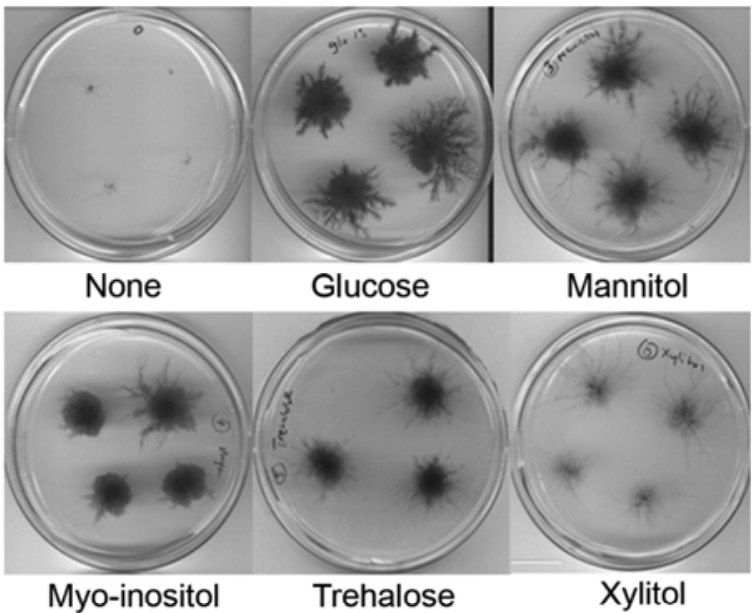

B
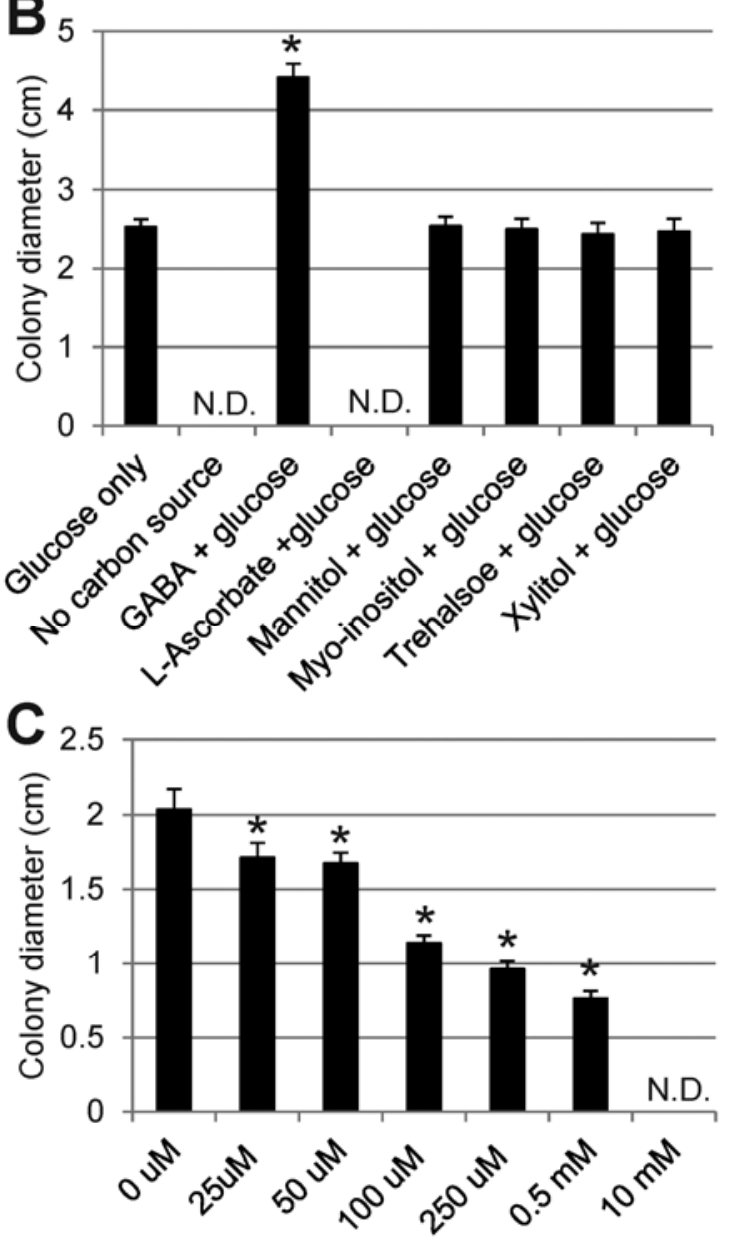

Ascorbate concentration

Fig. 4. Effects of various metabolites on growth of Alternaria brassicicola in culture. A, Minimal media containing no carbon source (none) or $1 \%$ (wt/vol) of the indicated compounds was inoculated with A. brassicicola by placing 2- $\mu \mathrm{l}$ droplets of a spore suspension in three or four places on each plate. Plates were photographed 2 weeks after inoculation. No growth was observed when gamma amino-butyric acid (GABA) or ascorbic acid were provided as carbon sources (not shown). B, Minimal media containing $1 \%$ glucose and $20 \mathrm{mM}$ indicated compounds were inoculated with $A$. brassicicola as in A. Diameters of colonies were measured after 7 days. C, Minimal media containing 1\% glucose and the indicated concentration of ascorbate. Diameters of colonies were measured after 5 days. For B and C, bars represent means and standard deviation of seven to eight colonies. Asterisks indicate significant differences from glucose alone (two-tailed $t$ test, $P<0.05)$. N.D. indicates that no fungal growth was detected.
Levels of reduced ascorbate and total ascorbate+DHA dropped following A. brassicicola inoculation, whereas levels of the oxidized form, DHA, rose by $24 \mathrm{~h}$. Consequently, the redox balance of the plant tissue became more oxidized. This could be an effect of reactive oxygen species produced by the plant as part of its defense response. Near-elimination of ascorbate was observed in Arabidopsis leaves infected with the
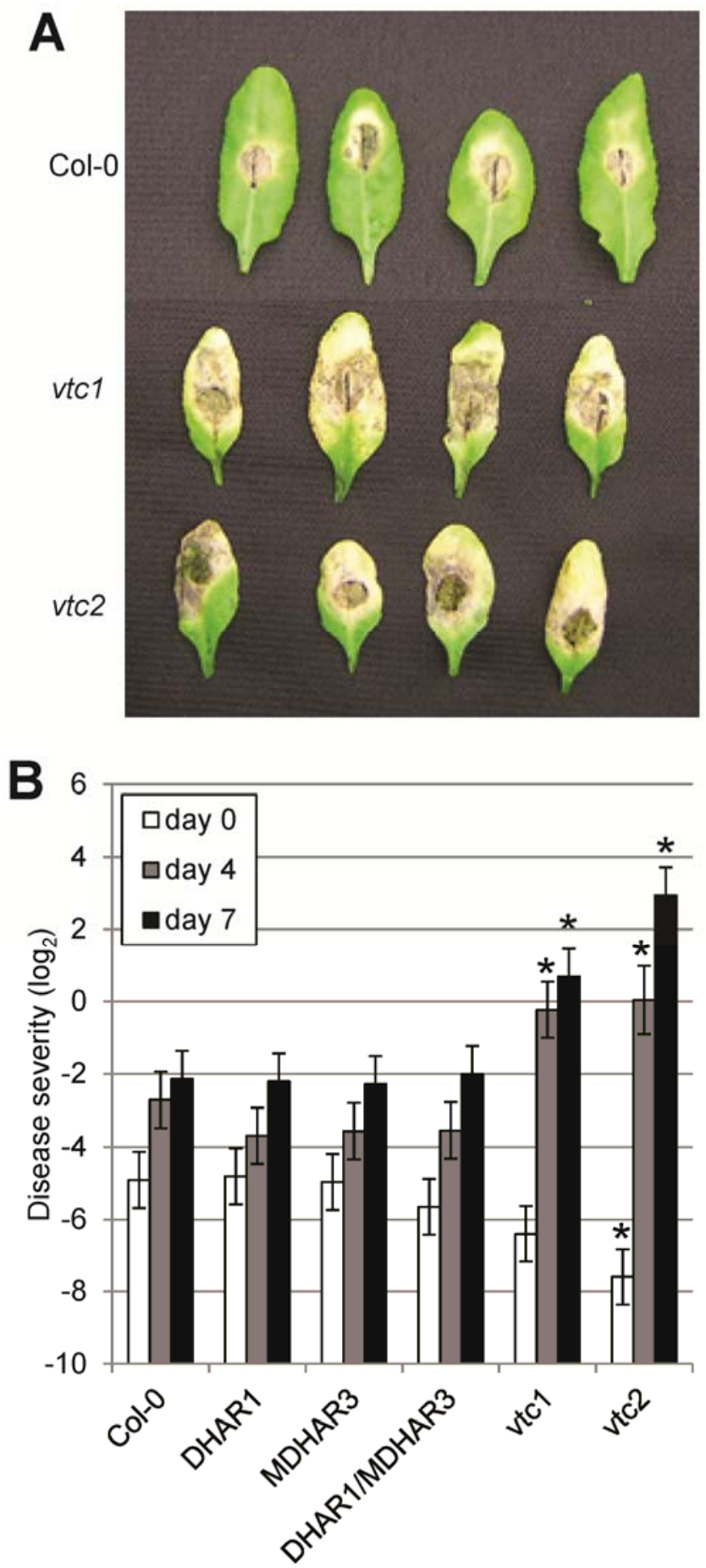

Fig. 5. Reduced plant ascorbate levels enhance Alternaria brassicicola disease severity. A, Leaves of Col-0, vtcl, and $v t c 27$ days after inoculation. B, Disease severity determined by quantitative polymerase chain reaction at 0 , 4, and 7 days after inoculation. Data were obtained in two independent experiments, each with two technical replicates, and combined using a mixed linear model. Bars are mean and standard error. Different letters indicate statistically significant differences $(P<0.05)$. DHAR $=$ dehydroascorbate reductase and MDHAR = monodehydroascorbate reductase. 
virulent necrotrophic fungus Botrytis cinerea (Muckenschnabel et al. 2002) but the effect of host ascorbate on $B$. cinerea is not known. Concomitant with the decline in ascorbate levels after inoculation, we observed an increase in threonic acid (Table 1). Oxidation of ascorbate produces threonic acid in vitro (Deutsch 1998; Isbell and Frush 1979). In many plants, oxidation of DHA leads to its conversion to oxalic acid and threonic acid (Green and Fry 2005). Thus, during inoculation, ascorbate levels may decline due to oxidation to DHA and further oxidation to threonic acid.

Addition of ascorbate to inoculation droplets reduced disease severity and addition of ascorbate to culture media reduced A. brassicicola growth. High levels of ascorbate can be toxic to cells. Ascorbate can reduce $\mathrm{Fe}^{3+}$ or $\mathrm{Cu}^{2+}$, which then react with hydrogen peroxide to produce hydroxide ions and toxic hydroxyl radicals, in a process called the Fenton reaction (Du et al. 2012). Any DHA produced in the medium by oxidation of ascorbate can enter cells. DHA can be recycled to ascorbate in cells using glutathione as the reducing agent. Excess DHA can be toxic by driving down glutathione levels (Du et al. 2012; Foyer and Noctor 2011). However, various fungi in which ascorbate metabolism has been studied have been found not to produce ascorbate but, rather, D-erythroascorbate (Smirnoff et al. 2004). Thus, they do not recycle DHA to ascorbate using glutathione. Although production of ascorbate by $A$. brassicicola has not been investigated, it is likely that it produces D-erythroascorbate and not ascorbate.

Plants with reduced ascorbate levels due to $v t c 1$ or $v t c 2$ mutations showed enhanced susceptibility to A. brassicicola, indicating that wild-type levels of ascorbate are important for resistance. There are several possibilities for the underlying mechanism. Ascorbate could play a direct anti-fungal role through toxic effects on $A$. brassicicola of ascorbate released from dying plant cells. Alternatively, there could be an indirect effect from changes in the host cells resulting from reduced ascorbate. Both vtc mutants have elevated levels of SA and hydrogen peroxide and show spots of spontaneous cell death (Barth et al. 2004; Mukherjee et al. 2010; Pavet et al. 2005). Because resistance to biotrophs is strongly promoted by elevated SA, this phenotype may explain resistance of $v t c$ mutants to certain biotrophic or hemi-biotrophic pathogens, including Hyaloperonspora arabidopsidis (formerly Peronospora parasitica) and Pseudomonas syringae (Barth et al. 2004; Pavet et al. 2005). Indeed, vtcl eds5 and vtcl nprl double mutants, in which SA signaling is blocked, support the same levels of $P$. syringae growth as eds5 and nprl single mutants, respectively, suggesting that the observed resistance of $v t c 1$ and $v t c 2 \mathrm{mu}-$ tants was due to elevated SA (Mukherjee et al. 2010). Elevated levels of SA are known to promote A. brassicicola growth by inhibiting JA signaling (Spoel et al. 2007); therefore, it is possible that the elevated SA levels in $v t c$ mutants are also responsible for the increased $A$. brassicicola disease severity. However, other effects of $v t c$ mutations may also play a role. As a necrotroph, A. brassicicola is expected to grow better in conditions that promote host cell death. The spontaneous lesions of vtc mutants might promote A. brassicicola growth. Consistent with this idea, bakl mutants, which undergo spreading cell death upon pathogen challenge, show increased disease severity when
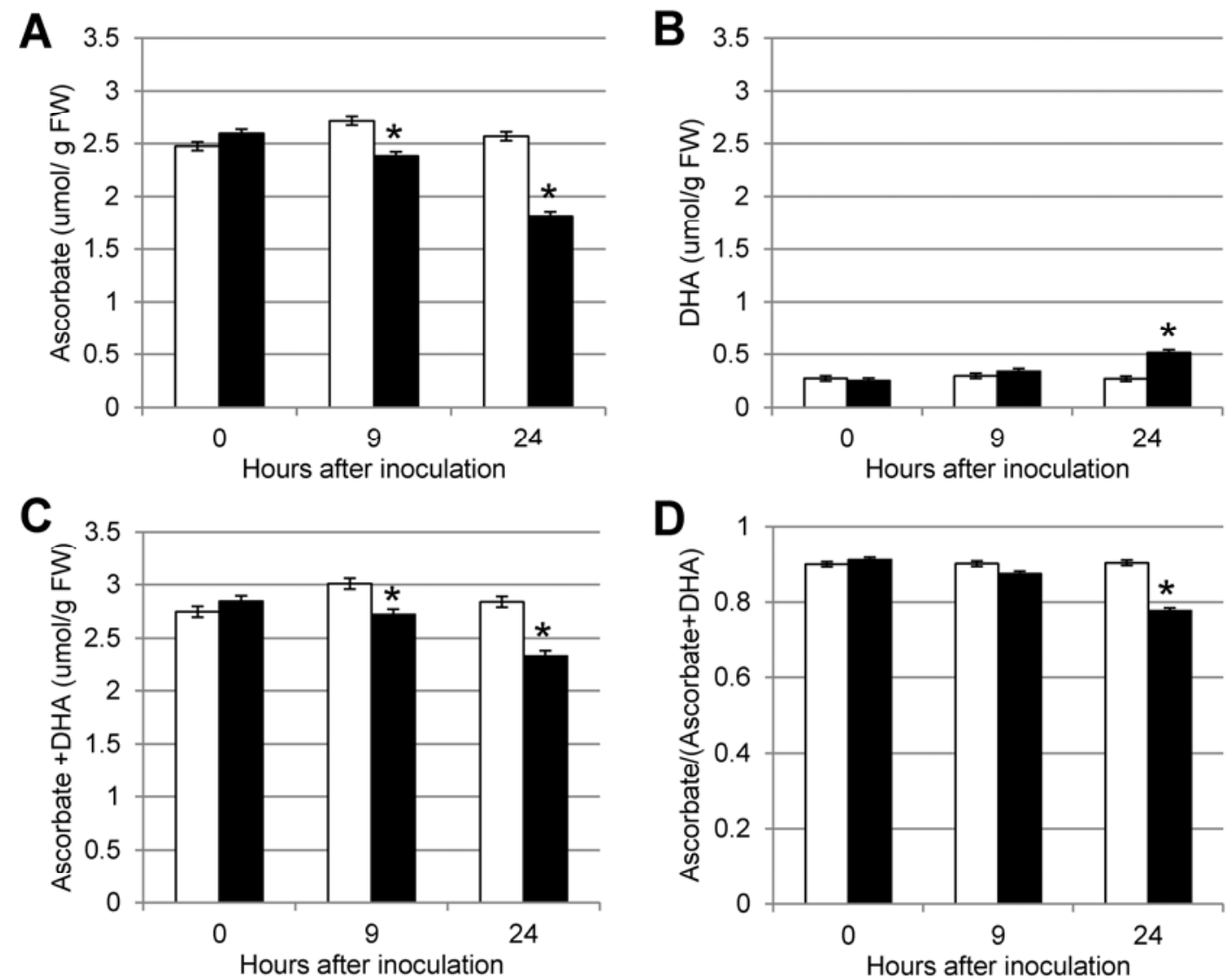

Fig. 6. Levels of ascorbate in plants inoculated with Alternaria brassicicola. A, Ascorbate; B, dehydroascorbate (DHA); C, total ascorbate and DHA; D, ratio of ascorbate to total ascorbate and DHA. Data were obtained in three independent biological replicates, each consisting of one sample per time-treatment combination. In each sample, levels of ascorbate and reduced ascorbate (representing ascorbate and DHA) were determined by high-performance liquid chromatography. Levels of DHA and the ratio of ascorbate to ascorbate and DHA were derived from the measured values. Means and standard errors were obtained using a mixed linear model. Asterisks indicate statistically significant differences between mock- and $A$. brassicicola-inoculated plants $(P<0.01)$. 
inoculated with A. brassicicola (Kemmerling et al. 2007). Although spontaneous lesions had not yet developed in the plants used in our experiments, they may have a tendency to undergo cell death more readily than wild-type plants, providing an advantage to the fungus. It is also possible that $v t c$ mutants have reduced ability to protect cellular components from oxidative damage during the oxidative burst associated with defense and that this may adversely impact effective immune responses.

We have shown that inoculation of Arabidopsis with A. brassicicola causes drastic changes in the metabolic profile. Some of the metabolites undergoing changes affect $A$. brassicicola disease severity when added to inoculation droplets. These include ascorbate, an important regulator of cellular redox status. Plant mutants with reduced levels of ascorbate were more susceptible to A. brassicicola, demonstrating that ascorbate is an important component of resistance. The metabolites that we have identified form the basis for future work addressing the roles of various metabolites in the $A$. brassicicola-Arabidopsis interaction.

\section{MATERIALS AND METHODS}

\section{Plant materials, growth conditions, and the preparation of inoculum.}

All mutants used in this study were in the background of Arabidopsis thaliana accession Col-0, unless noted otherwise. The mutants ein2-1 (Alonso et al. 1999), dde2-2 (von Malek et al. 2002), sid2-2 (Wildermuth et al. 2001), vtcl-1 (Conklin et al. 1997), and vtc2-1 (Conklin et al. 2000) have been previously described. Plants were grown in a controlled environment chamber (Conviron, Pembina, ND, U.S.A.) at $22^{\circ} \mathrm{C}$ with a 12 -h photoperiod $\left(100 \mu \mathrm{M} \mathrm{m}^{-2} \mathrm{~s}^{-1}\right.$ fluorescent illumination) and $70 \%$ relative humidity $(\mathrm{RH})$. Alternaria brassicicola strain ATCC96836 was grown on potato dextrose agar (BD, Franklin Lakes, NJ, U.S.A.) by evenly placing four 5- $\mu$ l droplets of stock inoculum on the plate and incubating for 10 days at room temperature with a 12-h photoperiod $\left(75 \mu \mathrm{M} \mathrm{m}^{-2} \mathrm{~s}^{-1}\right.$ fluorescent illumination). Subsequently, the spores were washed from the surface of the plate with $0.02 \%$ Tween-20, and fungal hyphae were removed from the suspension by filtering twice through four layers of cheesecloth. The concentration of spores was determined using a hemacytometer and adjusted to $1 \times 10^{5}$ spores $/ \mathrm{ml}$. For the foliar application of metabolites, the metabolites were added to a final concentration of 10 or 100 $\mathrm{mM}$ in $0.02 \%$ Tween 20 containing $1 \times 10^{5}$ spores $/ \mathrm{ml}$.

\section{Metabolite profiling.}

Samples for metabolite profiling were obtained in six independent replicate experiments. For each experiment, mockand $A$. brassicicola-infected samples were collected 9 and $24 \mathrm{~h}$ after inoculation by excising inoculation sites using a cork borer. Samples from multiple leaves were pooled to generate 50-mg samples for each genotype-treatment combination. From these pools, $20 \mathrm{mg}$ of frozen plant tissue was homogenized using a Retsch ball mill and subsequently extracted with $1 \mathrm{ml}$ of a carefully degassed (by sparging with nitrogen gas for $5 \mathrm{~min}$ ) (Fiehn et al. 2008) $-20^{\circ} \mathrm{C}$ cold chloroform $/ \mathrm{methanol} /$ water mixture $(2: 5: 2, \mathrm{vol} / \mathrm{vol} / \mathrm{vol})$ for $5 \mathrm{~min}$ at $4^{\circ} \mathrm{C}$. After centrifugation, half of the supernatant was dried and metabolites were derivatized by methoximation and trimethylsilylation, as published previously (Fiehn et al. 2008). Sample $(0.5 \mu \mathrm{l})$ was injected into multi-baffled liners and automatic liner exchange was performed for every 10 samples into a Gerstel CIS cold injector at an initial temperature of $50^{\circ} \mathrm{C}$ (ramped by $12^{\circ} \mathrm{C} \mathrm{s}^{-1}$ to $250^{\circ} \mathrm{C}$ ) in splitless mode. Chromatography was performed on an Agilent 6890 gas chromatograph with a Restek 30-by- $0.25-\mathrm{mm}$ i.d. by $0.25-\mu \mathrm{m}$ Rtx-5Sil MS column with $10-\mathrm{m}$ integrated guard column at a constant flow of helium of $1 \mathrm{ml} \mathrm{min}{ }^{-1}$ starting at $50^{\circ} \mathrm{C}$ for $1 \mathrm{~min}$, and then ramped at $20^{\circ} \mathrm{C} \mathrm{min}^{-1}$ to $330^{\circ} \mathrm{C}$. Electron ionization mass spectra were acquired at +70 $\mathrm{eV}$ from m/z 85 to 500 at 20 spectra s$^{-1}$ for 20-min run times. Chromatogram acquisition, data handling, automated peak deconvolution, and export of spectra was automatically performed by the Leco ChromaTOF software (v2.32). Data were further processed using the algorithms implemented in the open-source BinBase metabolome database (Fiehn et al. 2005). Metabolites were identified using the Fiehnlib libraries (Kind et al. 2009). To be included in the profiles, a metabolite had to be detected in at least four or five samples of the same type. Missing values were replaced from baseline-subtracted raw data for each individual compound using the BinBase algorithm (Fiehn et al. 2008). Result files were normalized to the sum intensities of all structurally identified compounds. Metabolite levels were expressed on a $\log _{2}$ scale, because this transformation resulted in a more normal distribution. To identify statistically significant differences in metabolite levels, data were analyzed in two different mixed linear models. In the first model, genotype, treatment, and time were considered as fixed factors and experimental replicate as a random factor. In the second model, only treatment and time were considered as fixed factors and experimental replicate was a random factor. $P$ values were corrected for multiple testing using Storey's false discovery rate, yielding $q$ values (Storey and Tibshirani 2003). All statistical analyses were conducted in the R environment ( $\mathrm{R}$ Development Core Team 2011).

Venn diagrams were drawn using the Venn Diagram Plotter from the Biological MS Data and Software Distribution Center of the Pacific Northwest National Laboratory.

\section{qPCR disease severity assay.}

Three-week-old plants were inoculated by placing one $10-\mu l$ droplet of spore suspension onto the adaxial surface of each leaf. Inoculated plants were covered with a transparent dome and kept at $100 \% \mathrm{RH}$ and $22^{\circ} \mathrm{C}$ with a 12 -h photoperiod for the duration of the experiment. Infection sites were excised from leaves using a cork borer. Eight leaves were pooled for each sample, and DNA was isolated. The relative amount of $A$. brassicicola DNA (cutinase A) to plant DNA (iASK, $\alpha$-Shaggy kinase) was determined by qPCR, as described previously (Tsuda et al. 2009). qPCR analysis was carried out using an ABI 7500 Real Time PCR system (Applied Biosystems, Foster City, CA, U.S.A.) and the Platinum SYBR Green qPCR SuperMix-UDG w/ROX (Invitrogen, Carlsbad, CA, U.S.A.). The primer sequences were 5' GCATGTCCGCTCACCAATATC 3' and $5^{\prime}$ GCCTGGGATCTTGGAATGC $3^{\prime}$ for cutinase A and $5^{\prime}$ CTTATCGGATTTCTCTATGTTTGGC 3' and 5' GAGCTCC TGTTTATTTAACTTGTACATACC 3 ' for iASK.

\section{A. brassicicola growth on minimal media.}

Minimal medium consisted of agar $(0.75 \%),\left(\mathrm{NH}_{4}\right)_{2} \mathrm{SO}_{4}$ (0.5\%), $\mathrm{KH}_{2} \mathrm{PO}_{4}(0.2 \%), \mathrm{MgSO}_{4}(0.06 \%), \mathrm{CaCl}_{2}(0.06 \%)$, $\mathrm{FeSO}_{4} \cdot 7 \mathrm{H}_{2} \mathrm{O}(0.0005 \%), \mathrm{MnSO}_{4} \cdot \mathrm{H}_{2} \mathrm{O}(0.00016 \%), \mathrm{ZnSO}_{4} \cdot$ $7 \mathrm{H}_{2} \mathrm{O}(0.00014 \%)$, and $\mathrm{CoCl}_{2} \cdot 6 \mathrm{H}_{2} \mathrm{O}(0.00037 \%)$. Following autoclaving, glucose $(1 \%)$ or filter-sterilized compounds were added. Plates were inoculated by evenly placing four 5- $\mu$ l droplets of stock inoculum onto the plates. These were incubated for 7 days at room temperature with a $12-\mathrm{h}$ photoperiod. Diameters of fungal colonies were measured.

\section{Isolation and expression of wheat DHAR and maize MDHAR.}

Full-length wheat DHAR cDNA was isolated and cloned as described (Chen et al. 2003). Full-length maize MDHAR 
cDNA was obtained from total maize cDNA following its amplification by PCR using the forward primer 5'-CGGA CTCCATGGTCACTGTAGTTCGATCG- $3^{\prime}$ and the reverse primer 5'-ACCAGGGATCCAGAAGAACCTTCACGATGA C-3'. The MDHAR cDNA isolated (GenBank accession number AY103967) was introduced into pGEM-T vector (Promega Corp., Madison, WI, U.S.A.).

\section{DHAR and MDHAR transgenic plants.}

Wild-type Col-0 plants were transformed using the floraldip method (Clough and Bent 1998), using Agrobacterium tumefaciens AGLO1 containing the DHAR or MDHAR transgenes in the binary vectors pBI121 or pFGC5941 (McGinnis et al. 2005), respectively. Seed of infiltrated plants were collected and screened on $\times 0.5$ Murashige Skoog, vancomycin at $500 \mu \mathrm{g} / \mathrm{ml}$ plates containing kanamycin at $50 \mu \mathrm{g} / \mathrm{ml}$ (DHAR) or glufosinate ammonium at $50 \mu \mathrm{g} / \mathrm{ml}$ (MDHAR). Plants homozygous for each transgene were identified in the T2 generation. Homozygous DHAR/MDHAR plants were obtained from crosses of DHAR and MDHAR transgenic parent plants and progeny containing both transgenes were selected in the F2 population by their kanamycin and glufosinate ammonium resistance, and homozygous double transgenics were isolated.

\section{Determination of ascorbate by HPLC.}

HPLC analysis of Asc and DHA was performed as described (Conklin et al. 2000). Following grinding with liquid nitrogen, $100 \mathrm{mg}$ of leaf powder was extracted with $0.5 \mathrm{ml}$ of $0.2 \%$ metaphosphoric acid containing $0.54 \mathrm{mM} \mathrm{Na}_{2}$ EDTA and $0.01 \%$ polyvinylpolypyrrolidone. Extracts were centrifuged for $10 \mathrm{~min}$ at $4^{\circ} \mathrm{C}$ to remove cell debris and the supernatant was passed through a $0.25-\mu \mathrm{m}$ filter. Then, $20 \mu \mathrm{l}$ of the leaf extract was injected onto a C-18 octadecylsilane column and eluted with isocratic mobile phase $(20 \mathrm{mM} \mathrm{NaAc}, 0.54 \mathrm{mM}$ $\mathrm{Na}_{2}$ EDTA, $1.5 \mathrm{mM} \mathrm{N}$-octylamine) at a flow rate of $0.5 \mathrm{ml} / \mathrm{min}$. The Asc peak was identified and quantitated using Asc standards. DHA was measured by neutralizing the leaf extract with $0.5 \mathrm{M} \mathrm{NaOH}$ to $\mathrm{pH} 6.5$ and reducing the DHA to Asc using $2.5 \mathrm{mM}$ glutathione and $2 \mathrm{ng}$ of recombinant DHAR for 20 min at room temperature prior to HPLC quantitation. The level of DHA was determined from the difference between the amount of Asc and the total amount of Asc (i.e., Asc + DHA).

\section{ACKNOWLEDGMENTS}

We thank P. Conklin for vtc1-1 and $v t c 2-1$, L. Nguyen for technical support, the Arabidopsis Biological Resource Center for T-DNA insertion lines, F. Katagiri for assistance with statistical analysis, S. Shahbaz for technical assistance in metabolite profiling, K. Tsuda for helpful discussions, and an anonymous reviewer whose comments helped us improve the Discussion. Metabolite profiling was funded by National Science Foundation grant MCB 1139644 to O. Fiehn. Measurement of ascorbate levels was funded by National Science Foundation grant DBI-0820047 to D. R. Gallie. All other work was funded by the Division of Chemical Sciences, Geosciences, and Biosciences, Office of Basic Energy Sciences of the United States Department of Energy through Grant DE-FG02-05ER15670 to J. Glazebrook. C. J. Botanga conducted all experiments except as noted below, contributed to design of the overall study and interpretation of data, and wrote parts of Materials and Methods. G. Bethke prepared samples used in Figure 6, conducted experiments shown in Supplementary Figure S2, contributed to design and interpretation of these experiments, and wrote parts of Materials and Methods. Z. Chen and D. R. Gallie produced the DHAR and MDHAR overexpression lines, conducted ascorbate assays shown in Figure 6 and Supplementary Figure S3, and wrote parts of Materials and Methods. O. Fiehn conducted metabolite profiling experiments, analyzed the data, and wrote parts of Materials and Methods. J Glazebrook contributed to design of the overall study, analyzed data, prepared figures, and wrote the manuscript. All authors critically reviewed the manuscript.

\section{LITERATURE CITED}

Alonso, J. M., Hirayama, T., Roman, G., Nourizadeh, S., and Ecker, J. R. 1999. EIN2, a bifunctional transducer of ethylene and stress responses in Arabidopsis. Science 284:2148-2152.

Barth, C., Moeder, W., Klessig, D. F., and Conklin, P. L. 2004. The timing of senescence and response to pathogens is altered in the ascorbate-deficient Arabidopsis mutant vitamin c-1. Plant Physiol. 134:1784-1792.

Berr, A., McCallum, E. J., Alioua, A., Heintz, D., Heitz, T., and Shen, W. H. 2010. Arabidopsis histone methyltransferase SET DOMAIN GROUP8 mediates induction of the jasmonate/ethylene pathway genes in plant defense response to necrotrophic fungi. Plant Physiol. 154:1403-1414.

Böttcher, C., Westphal, L., Schmotz, C., Prade, E., Scheel, D., and Glawischnig, E. 2009. The multifunctional enzyme CYP71B15 (PHYTOALEXIN DEFICIENT3) converts cysteine-indole-3-acetonitrile to camalexin in the indole-3-acetonitrile metabolic network of Arabidopsis thaliana. Plant Cell 21:1830-1845.

Bouché N, Fait A, Zik M, Fromm H. 2004. The root-specific glutamate decarboxylase (GAD1) is essential for sustaining GABA levels in Arabidopsis. Plant Mol Biol. 55:315-25.

Chen, Z., Young, T. E., Ling, J., Chang, S. C., and Gallie, D. R. 2003. Increasing vitamin $\mathrm{C}$ content of plants through enhanced ascorbate recycling. Proc. Natl. Acad. Sci. U.S.A.100:3525-3530.

Clough, S. J., and Bent, A. F. 1998. Floral dip: A simplified method for Agrobacterium-mediated transformation of Arabidopsis thaliana. Plant J. 16:735-743.

Conklin, P. L., Pallanca, J. E., Last, R. L., and Smirnoff, N. 1997. L-ascorbic acid metabolism in the ascorbate-deficient Arabidopsis mutant vtc1. Plant Physiol. 115:1277-1285.

Conklin, P. L., Norris, S. R., Wheeler, G. L., Williams, E. H., Smirnoff, N., and Last, R. L. 1999. Genetic evidence for the role of GDP-mannose in plant ascorbic acid (vitamin C) biosynthesis. Proc. Natl. Acad. Sci. U.S.A.96:4198-4203.

Conklin, P. L., Saracco, S. A., Norris, S. R., and Last, R. L. 2000. Identification of ascorbic acid-deficient Arabidopsis thaliana mutants. Genetics 154:847-856

Deutsch, J. C. 1998. Ascorbic acid oxidation by hydrogen peroxide. Anal. Biochem. 255:1-7.

Dowdle, J., Ishikawa, T., Gatzek, S., Rolinski, S., and Smirnoff, N. 2007. Two genes in Arabidopsis thaliana encoding GDP-L-galactose phosphorylase are required for ascorbate biosynthesis and seedling viability. Plant J. 52:673-689.

Du, J., Cullen, J. J., and Buettner, G. R. 2012. Ascorbic acid: Chemistry, biology and the treatment of cancer. Biochim. Biophys. Acta. 1826:443-457.

Fernandez, O., Béthencourt, L., Quero, A., Sangwan, R. S., and Clément, C. 2010. Trehalose and plant stress responses: Friend or foe? Trends Plant Sci. 15:409-417.

Fiehn, O., Wolgemuth, G., and Scholz, M. 2005. Setup and annotation of metabolomic experiments by integrating biological and mass spectrometric metadata. Proc. Lect. Notes Bioinf. 3615:224-239.

Fiehn, O., Wohlgemuth, G., Scholz, M., Kind, T., Lee, D. Y., Lu, Y., Moon, S., and Nikolau, B. 2008. Quality control for plant metabolomics: Reporting MSI-compliant studies. Plant J. 53:691-704.

Foyer, C. H., and Noctor, G. 2011. Ascorbate and glutathione: The heart of the redox hub. Plant Physiol. 155:2-18.

Gachon, C., and Saindrenan, P. 2004. Real-time PCR monitoring of fungal development in Arabidopsis thaliana infected by Alternaria brassicicola and Botrytis cinerea. Plant Physiol. Biochem. 42:367-371.

Glawischnig, E., Hansen, B. G., Olsen, C. E., and Halkier, B. A. 2004 Camalexin is synthesized from indole-3-acetaldoxime, a key branching point between primary and secondary metabolism in Arabidopsis. Proc. Natl. Acad. Sci. U.S.A. 101:8245-8250.

Glazebrook, J. 2005. Contrasting mechanisms of defense against biotrophic and necrotrophic pathogens. Annu. Rev. Phytopathol. 43:205227.

Green, M. A., and Fry, S. C. 2005. Vitamin C degradation in plant cells via enzymatic hydrolysis of 4-O-oxalyl-L-threonate. Nature 433:83-87.

Hull, A. K., Vij, R., and Celenza, J. L. 2000. Arabidopsis cytochrome $\mathrm{P} 450$ s that catalyze the first step of tryptophan-dependent indole-3-acetic acid biosynthesis. Proc. Natl. Acad. Sci. U.S.A. 97:2379-2384.

Isbell, H. S., and Frush, H. L. 1979. Reactions of carbohydrates with hydroperoxides. 11. Oxidation of L-ascorbic-acid by hydrogen-peroxidePreparation of L-threonic acid. Carbohydr. Res. 72:301-304.

Jennings, D. B., Ehrenshaft, M., Pharr, D. M., and Williamson, J. D. 1998. Roles for mannitol and mannitol dehydrogenase in active oxygen-mediated plant defense. Proc. Natl. Acad. Sci. U.S.A. 95:15129-15133.

Jennings, D. B., Daub, M. E., Pharr, D. M., and Williamson, J. D. 2002. Constitutive expression of a celery mannitol dehydrogenase in tobacco enhances resistance to the mannitol-secreting fungal pathogen Alternaria alternata. Plant J. 32:41-49. 
Jones, J. D., and Dangl, J. L. 2006. The plant immune system. Nature 444:323-329.

Kagan, I. A., and Hammerschmidt, R. 2002. Arabidopsis ecotype variability in camalexin production and reaction to infection by Alternaria brassicicola. J. Chem. Ecol. 28:2121-2140.

Kemmerling, B., Schwedt, A., Rodriguez, P., Mazzotta, S., Frank, M., Qamar, S. A., Mengiste, T., Betsuyaku, S., Parker, J. E., Mussig, C., Thomma, B. P. H. J., Albrecht, C., de Vries, S.C., Hirt, H., and Nurnberger, T. 2007. The BRI1-associated kinase 1, BAK1, has a brassinolide-independent role in plant cell-death control. Curr. Biol. 17:1116-1122.

Kind, T., Wohlgemuth, G., Lee, D. Y., Lu, Y., Palazoglu, M., Shahbaz, S., and Fiehn, O. 2009. FiehnLib: Mass spectral and retention index libraries for metabolomics based on quadrupole and time-of-flight gas chromatography/mass spectrometry. Anal. Chem. 81:10038-10048.

Leyman, B., Van Dijck, P., and Thevelein, J. M. 2001. An unexpected plethora of trehalose biosynthesis genes in Arabidopsis thaliana. Trends Plant Sci. 6:510-513.

Linster, C. L., Gomez, T. A., Christensen, K. C., Adler, L. N., Young, B. D., Brenner, C., and Clarke, S. G. 2007. Arabidopsis VTC2 encodes a GDP-L-galactose phosphorylase, the last unknown enzyme in the Smirnoff-Wheeler pathway to ascorbic acid in plants. J. Biol. Chem. 282:18879-18885.

McGinnis, K., Chandler, V., Cone, K., Kaeppler, H., Kaeppler, S., Kerschen, A., Pikaard, C., Richards, E., Sidorenko, L., Smith, T., Springer, N., and Wulan, T. 2005. Transgene-induced RNA interference as a tool for plant functional genomics. Methods Enzymol. 392:1-24.

Mikkelsen, M. D., Hansen, C. H., Wittstock, U., and Halkier, B. A. 2000. Cytochrome P450 CYP79B2 from Arabidopsis catalyzes the conversion of tryptophan to indole-3-acetaldoxime, a precursor of indole glucosinolates and indole-3-acetic acid. J. Biol. Chem. 275:33712-33717.

Muckenschnabel, I., Goodman, B.A., Williamson, B., Lyon, G. D., and Deighton, N. 2002. Infection of leaves of Arabidopsis thaliana by Botrytis cinerea: Changes in ascorbic acid, free radicals and lipid peroxidation products. J. Exp. Bot. 53:207-214.

Mukherjee, M., Larrimore, K. E., Ahmed, N. J., Bedick, T. S., Barghouthi, N. T., Traw, M. B., and Barth, C. 2010. Ascorbic acid Deficiency in Arabidopsis induces constitutive priming that is dependent on hydrogen peroxide, salicylic acid, and the NPR1 gene. Mol. Plant-Microbe Interact. 23:340-351.

Nafisi, M., Goregaoker, S., Botanga, C.J., Glawischnig, E., Olsen, C. E., Halkier, B. A., and Glazebrook, J. 2007. Arabidopsis cytochrome P450 monooxygenase 71A13 catalyzes the conversion of indole-3-acetaldoxime in camalexin synthesis. Plant Cell 19:2039-2052.

Oh, I. S., Park, A. R., Bae, M. S., Kwon, S. J., Kim, Y. S., Lee, J. E., Kang, N. Y., Lee, S., Cheong, H., and Park, O. K. 2005. Secretome analysis reveals an Arabidopsis lipase involved in defense against Alternaria brassicicola. Plant Cell 17:2832-2847.

Otani, H., Kohnobe, A., Kodama, M., and Kohmoto, K. 1998. Production of a host-specific toxin by germinating spores of Alternaria brassicicola. Physiol. Mol. Plant Pathol. 52:285-295.

Palanivelu, R., Brass, L., Edlund, A. F., and Preuss, D. 2003. Pollen tube growth and guidance is regulated by $P O P 2$, an Arabidopsis gene that controls GABA levels. Cell 114:47-59.

Parisy, V., Poinssot, B., Owsianowski, L., Buchala, A., Glazebrook, J., and Mauch, F. 2007. Identification of PAD2 as a $\gamma$-glutamylcysteine synthetase highlights the importance of glutathione in disease resistance of Arabidopsis. Plant J. 49:159-172.

Park, D. H., Mirabella, R., Bronstein, P. A., Preston, G. M., Haring, M. A., Lim, C. K., Collmer, A., and Schuurink, R. C. 2010. Mutations in gamma-aminobutyric acid (GABA) transaminase genes in plants or Pseudomonas syringae reduce bacterial virulence. Plant J. 64:318330

Paul, M. J., Primavesi, L. F., Jhurreea, D., and Zhang, Y. H. 2008. Trehalose metabolism and signaling. Annu. Rev. Plant Biol. 59:417-441.

Pavet, V., Olmos, E., Kiddle, G., Mowla, S., Kumar, S., Antoniw, J., Alvarez, M. E., and Foyer, C. H. 2005. Ascorbic acid deficiency activates cell death and disease resistance responses in Arabidopsis. Plant Physiol. 139:1291-1303.

Pegadaraju, V., Louis, J., Singh, V., Reese, J. C., Bautor, J., Feys, B. J., Cook, G., Parker, J. E., and Shah, J. 2007. Phloem-based resistance to green peach aphid is controlled by Arabidopsis PHYTOALEXIN DEFICIENT4 without its signaling partner ENHANCED DISEASE SUSCEPTIBILITY1. Plant J. 52:332-341

Penninckx, I. A., Thomma, B. P., Buchala, A., Metraux, J. P., and Broekaert, W. F. 1998. Concomitant activation of jasmonate and ethylene response pathways is required for induction of a plant defensin gene in Arabi- dopsis. Plant Cell 10:2103-2113.

R Development Core Team. 2011. R: A Language and Environment for Statistical Computing, R Foundation for Statistical Computing Computing, Vienna.

Robert-Seilaniantz, A., Grant, M., and Jones, J. D. G. 2011a. Hormone crosstalk in plant disease and defense: More than just JASMONATESALICYLATE antagonism. Annu. Rev. Phytopathol. Vol 49 49:317-343.

Robert-Seilaniantz, A., MacLean, D., Jikumaru, Y., Hill, L., Yamaguchi, S., Kamiya, Y., and Jones, J. D. G. 2011b. The microRNA miR393 redirects secondary metabolite biosynthesis away from camalexin and towards glucosinolates. Plant J. 67:218-231.

Schuhegger, R., Nafisi, M., Mansourova, M., Petersen, B. L., Olsen, C. E., Svatos, A., Halkier, B. A., and Glawischnig, E. 2006. CYP71B15 (PAD3) catalyzes the final step in camalexin biosynthesis. Plant Physiol. 141:1248-1254.

Shelp, B. J., Bown, A. W., and McLean, M. D. 1999. Metabolism and functions of gamma-aminobutyric acid. Trends Plant Sci. 4:446-452.

Singh, V., Louis, J., Ayre, B. G., Reese, J. C., and Shah, J. 2011. TREHALOSE PHOSPHATE SYNTHASE11-dependent trehalose metabolism promotes Arabidopsis thaliana defense against the phloem-feeding insect Myzus persicae. Plant J. 67:94-104.

Smirnoff, N., Running, J. A., and Gatzek, S. 2004. Ascorbate biosynthesis: A diversity of pathways. Pages 7-29 in: Vitamin C: Its Functions and Biochemistry in Animals and Plants. H. Asard, J. M. May, and N. Smirnoff, eds. BIOS Scientific Publishers, Ltd., Oxford.

Spoel, S. H., and Dong, X. N. 2008. Making sense of hormone crosstalk during plant immune responses. Cell Host Microbe 3:348-351.

Spoel, S. H., Johnson, J. S., and Dong, X. 2007. Regulation of tradeoffs between plant defenses against pathogens with different lifestyles. Proc. Natl. Acad. Sci. U.S.A. 104:18842-18847.

Storey, J. D., and Tibshirani, R. 2003. Statistical significance for genomewide studies. Proc. Natl. Acad. Sci. U.S.A. 100:9440-9445.

Su, T. B., Xu, J. A., Li, Y. A., Lei, L., Zhao, L., Yang, H. L., Feng, J. D., Liu, G. Q., and Ren, D. T. 2011. Glutathione-indole-3-acetonitrile is required for camalexin biosynthesis in Arabidopsis thaliana. Plant Cell 23:364-380.

Thomma, B. P., Eggermont, K., Tierens, K. F., and Broekaert, W. F. 1999a. Requirement of functional ethylene-insensitive 2 gene for efficient resistance of Arabidopsis to infection by Botrytis cinerea. Plant Physiol. 121:1093-1102.

Thomma, B. P., Nelissen, I., Eggermont, K., and Broekaert, W. F. 1999b. Deficiency in phytoalexin production causes enhanced susceptibility of Arabidopsis thaliana to the fungus Alternaria brassicicola. Plant J. 19:163-171.

Thomma, B. P. H. J., Eggermont, K., Penninckx, I. A. M. A., Mauch-Mani, B., Vogelsang, R., Cammue, B. P. A., and Broekaert, W. F. 1998. Separate jasmonate-dependent and salicylate-dependent defense-response pathways in Arabidopsis are essential for resistance to distinct microbial pathogens. Proc. Natl. Acad. Sci. U.S.A. 95:15107-15111.

Tsuda, K., Sato, M., Stoddard, T., Glazebrook, J., and Katagiri, F. 2009. Network properties of robust immunity in plants. PLoS Genet. 5:e1000772. Published online.

van Wees, S. C., Chang, H. S., Zhu, T., and Glazebrook, J. 2003. Characterization of the early response of Arabidopsis to Alternaria brassicicola infection using expression profiling. Plant Physiol. 132:606-617.

Vélëz, H., Glassbrook, N. J., and Daub, M. E. 2008. Mannitol biosynthesis is required for plant pathogenicity by Alternaria alternata. FEMS (Fed. Eur. Microbiol. Soc.) Microbiol. Lett. 285:122-129.

von Malek, B., van der Graaff, E., Schneitz, K., and Keller, B. 2002. The Arabidopsis male-sterile mutant dde2-2 is defective in the ALLENE OXIDE SYNTHASE gene encoding one of the key enzymes of the jasmonic acid biosynthesis pathway. Planta 216:187-192.

Ward, J. L., Forcat, S., Beckmann, M., Bennett, M., Miller, S. J., Baker, J. M., Hawkins, N. D., Vermeer, C. P., Lu, C. A., Lin, W. C., Truman, W. M., Beale, M. H., Draper, J., Mansfield, J. W., and Grant, M. 2010. The metabolic transition during disease following infection of Arabidopsis thaliana by Pseudomonas syringae pv. tomato. Plant J. 63:443-457.

Wildermuth, M. C., Dewdney, J., Wu, G., and Ausubel, F. M. 2001. Isochorismate synthase is required to synthesize salicylic acid for plant defence. Nature 414:562-565.

\section{AUTHOR-RECOMMENDED INTERNET RESOURCES}

The R project for statistical computing: www.r-project.org/

The Venn Diagram Plotter:

omics.pnl.gov/software/VennDiagramPlotter.php 